\title{
Inhibition of corrosion of mild steel in sea water by an aqueous extract of turmeric powder
}

\section{P. Mahalakshmi, ${ }^{1}$ S. Rajendran, ${ }^{2 *}$ G. Nandhini, ${ }^{1}$ S.C. Joycee, ${ }^{2}$ N. Vijaya, ${ }^{3}$ T. Umasankareswari ${ }^{4}$ and N. Renuga Devi ${ }^{5}$}

${ }^{1} P G$ Department of Chemistry, M.V. Muthiah Government Arts College for Women, Dindigul-624001, India

${ }^{2}$ Corrosion Research Centre, Department of Chemistry, St Antony's College of Arts and Science for Women, Dindigul-62405, India Affiliated to Mother Teresa Women's University, Kodaikanal, India ${ }^{3}$ Department of Chemistry, Vellalar College for Women, Thindal, Erode, India ${ }^{4}$ Department of Chemistry, Rajapalayam Raju's College, Rajapalayam, India ${ }^{5}$ Department of Zoology, GTN Arts College, Dindigul, India *E-mail: susairajendran@gmail.com

\begin{abstract}
An aqueous extract of turmeric powder (Curcuma longa) has been used as corrosion inhibitor, to control corrosion of mild steel in sea water. Methods such as weight loss method, polarization study and AC impedance spectra have been used. The protective film has been analyzed by UVvisible spectra, Fluorescence spectra and FTIR spectra. The surface morphology has been analyzed by SEM. The Hardness of a metal before and after immersion has been determined. Weight loss study reveals that the maximum corrosion inhibition efficiency of $98 \%$ is offered by $10 \mathrm{ml}$ of Turmeric extract. The adsorption study reveals that the active principles (Curcumin) are adsorbed on metal surface by Langmuir absorption isotherm. Polarization study reveals that the inhibitor function as cathodic inhibitor, because the corrosion potential is shifted to more negative side. AC impedance spectra confirm the formation of a protective film on the metal surface. Fluorescence spectra confirm that the protective film consists of $\mathrm{Fe}^{2+}-$ Curcumin complex formed on the anodic sites of the metal surface. This is confirmed by FTIR spectra. Vicker hardness (HV) study reveals that in presence of inhibitors, the hardness of the metal increases. In the absence of inhibitors (corrosive medium-sea water), the hardness of the metal decreases. These findings may be used in cooling water systems where sea water can be used as coolant.
\end{abstract}

Keywords: corrosion inhibition, green inhibitor, mild steel, turmeric powder, electrochemical studies, Vicker hardness.

Received: March 26, 2020. Published: May 27, 2020

doi: $\underline{10.17675 / 2305-6894-2020-9-2-20}$ 


\section{Introduction}

Corrosion is a natural and spontaneous process just like death. Corrosion is the gradual obliteration of materials by chemical and/or electrochemical reaction with their environment. Corrosion is a natural, spontaneous and thermodynamically favorable process, which converts a refined metal to a more chemically-stable form, such as its oxide, hydroxide, or sulfide. Corrosion is the expression of the desire of the metal to go back to its original state. For a metal to undergo corrosion, air (more precisely oxygen) and water are necessary. In the absence of any one corrosion will not take place. Usually pure metal will not undergo corrosion. However when impurity is introduced, the metal becomes nonhomogeneous in nature. Some sites act as anodes and some sites act as cathode. Anode has a tendency to lose electron and cathode has a tendency to accept the electron. For the electron transfer a medium, usually called, an electrolyte is needed. This event we call it corrosion [1]. There are many ways to control the rate of corrosion. One such method is use of inhibitors. To prevent corrosion of metals in solutions or in water (as in cooling water system) corrosion inhibitors are added to the environment. Due to environmental hazards caused by many inhibitors the recent trend is use of green inhibitors. Several research papers have been published in this regard. Jyothi et al. [2] have reviewed the use of green inhibitors. Rajendran et al. [3] have explained green solution to corrosion problems and also discussed the various methods employed in this field. Usually weight loss methods are adopted to measure the corrosion inhibition efficiencies. The mechanistic aspects have been investigated by electrochemical studies such as polarization study and AC impedance spectra. Sometimes noise measurement has also been used. The protective films formed on the metal surface have been analyzed by surface analysis techniques such as SEM, EDAX, FTIR and AFM. Experiments have been carried out at various temperatures also. Various adsorption isotherms have been proposed. Of all the metals and alloys used, mild steel has been extensively used. The experiments have been carried out in acid medium and neutral medium (sodium chloride). The extracts of the leaves contain many ingredients which have polar groups such as $\mathrm{N}, \mathrm{O}, \mathrm{S}$ and $\mathrm{P}$ atoms. The lone pair of electrons present on these atoms are pumped on to the metal surface. This controls the corrosion process. Inhibition effect of orange seed extract on aluminum corrosion in $1 \mathrm{M}$ hydrochloric acid solution has been investigated by Olawale et al. [4]. Coffee husk as corrosion inhibitor for mild steel in $\mathrm{HCl}$ media by Cordeiro et al. [5]. The inhibitor is adsorbed on the metal surface. The adsorption process obeys Langmuir isotherm. Umoren et al. have used ethanolic extracts of date palm leaves and seeds to control corrosion of carbon steel in $15 \% \mathrm{HCl}$ solution [6]. Potentiodynamic polarization study suggests that the extracts function as mixed type of inhibitors. Corrosion inhibition occurs by adsorption of components of the extract on the steel surface and was found to follow Langmuir adsorption isotherm model. Performance of Centaurea cyanus aqueous extract towards corrosion mitigation of carbon steel in saline formation water has been evaluated by El-Taib Heakal et al. [7]. Weight loss measurements, electrochemical impedance spectroscopy (EIS) and potentiodynamic polarization techniques 
have been used. SEM, EDAX and FTIR have been employed. A study of the gorse aqueous extract as a green corrosion inhibitor for mild steel in $\mathrm{HCl}$ aqueous solution has been reported by Trindade et al. [8]. The high-molecular-weight fraction isolated from the gorse extract showed high inhibition efficiencies. Parthipan et al. have used neem extract as a green inhibitor for microbiologically influenced corrosion of carbon steel API 5LX in a hypersaline environments [9]. Salhi et al. [10] have used natural product extract as eco-friendly corrosion inhibitor for mild steel in $1 \mathrm{M} \mathrm{HCl}$. The methanolic extract of Mentha Suaveolens (EMMS) has been studied as inhibitor mild steel in hydrochloric acid $(1 \mathrm{M} \mathrm{HCl})$ solution using by weight loss measurement, potentiodynamic polarization and electrochemical impedance spectroscopy (EIS) techniques. Al-Khaldi [11] has used natural products as corrosion inhibitor for steel in $0.5 \mathrm{M}$ hydrochloric acid solution. Lemon leaves extracts with saffron, almonds, guava leaves and Origanum majorana extracts have been used. Polarization study and AC impedance spectra have been used. Susai Rajendran and Gurmeet Singh have discussed the use of green inhibitors in controlling corrosion of metals and alloys [12]. Recent publications also discuss the use of green inhibitors [13-15].

The present work is undertaken $(i)$ to evaluate the inhibition efficiency of an aqueous extract of turmeric powder in controlling corrosion of mild steel in sea water, (ii) to study the mechanistic aspects of corrosion inhibition by electrochemical studies such as polarization study and AC impedance spectra, (iii) to study the surface morphology by SEM, (iv) to analyze the protective film by FTIR spectra and $(v)$ to determine the hardness of metal surface before and after corrosion inhibition.

\section{Experimental}

Weight loss method

Preparation of specimens

Mild steel specimens of dimensions $1.0 \times 4.0 \times 0.2 \mathrm{~cm}$, were polished to mirror finish, degreased with trichloroethylene, and used for the weight loss method and for surface examination studies. Weights of the polished mild steel specimens were determined before and after immersion in various test solutions. The inhibition efficiencies were calculated from the relation $\mathrm{IE}=\left[\left(W_{1}-W_{2}\right) / W_{1}\right] 100 \%$, where $W_{1}$ is corrosion rate in the absence of inhibitor and $W_{2}$ is the corrosion rate in the presence of inhibitor.

\section{Preparation of yellow inhibitor}

An aqueous extract of a plant material, namely, turmeric powder (Curcuma longa) has been prepared by boiling $10 \mathrm{~g}$ of shade dried turmeric powder, filtering the suspended impurities and making up to $100 \mathrm{ml}$ in a standard measuring flask. The extract was used to control the corrosion of mild steel in sea water. 


\section{Electrochemical studies}

In the present work corrosion resistance of mild steel immersed in various test solutions were measured by Polarization study and AC impedance spectra.

\section{Polarization study}

In the present study polarization studies were carried out in a CHI Electrochemical work station/analyzer, model 660A. It was provided with automatic IR compensation facility. A three electrode cell assembly was used (Scheme 1).

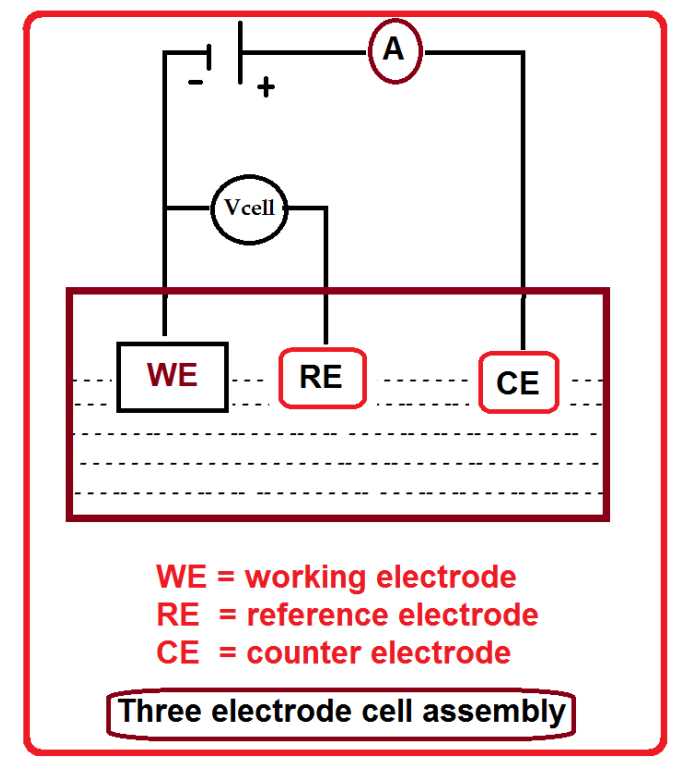

Scheme 1. Three electrode cell assembly.

The working electrode was mild steel. A SCE was the reference electrode. Platinum was the counter electrode. A time interval of 5 to $10 \mathrm{~min}$ was given for the system to attain a steady state open circuit potential. The working electrode and the platinum electrode were immersed in sea water in the absence and presence of inhibitor. Saturated calomel electrode was connected with the test solution through a salt bridge. From polarization study, corrosion parameters such as corrosion potential $\left(E_{\text {corr }}\right)$, corrosion current $\left(I_{\text {corr }}\right)$, Tafel slopes anodic $b_{\text {a }}$ and cathodic $b_{\mathrm{c}}$ and LPR (linear polarization resistance) value. The scan rate $(V / S)$ was 0.01 . Hold time at $\left(E_{\mathrm{fcs}}\right)$ was zero and quiet time (s) was two.

\section{AC Impedance spectra}

In the present investigation the same instrument and set-up used for polarization study was used to record AC impedance spectra also. A time interval of 5 to 10 min was given for the system to attain a steady state open circuit potential. The real part $\left(Z^{\prime}\right)$ and imaginary part $\left(Z^{\prime \prime}\right)$ of the cell impedance were measured in ohms at various frequencies. AC impedance spectra were recorded with initial $E(\mathrm{v})=0$, high frequency $\left(1 \times 10^{5} \mathrm{~Hz}\right)$, low frequency $(1 \mathrm{~Hz})$, amplitude $(\mathrm{V})=0.005$ and quiet time $(\mathrm{s})=2$. From Nyquist plot the values of charge transfer resistance $\left(R_{\mathrm{t}}\right)$ and the double layer capacitance $\left(C_{\mathrm{dl}}\right)$ were calculated. 


$$
R_{\mathrm{t}}=\left(R_{\mathrm{s}}+R_{\mathrm{t}}\right)-R_{\mathrm{s}}
$$

Where $R_{\mathrm{S}}$ is solution resistance.

$C_{\mathrm{dl}}$ values were calculated using the relationship

$$
C_{\mathrm{dl}}=1 / 2 \times 3.14 \times R_{\mathrm{t}} \times f_{\text {max }}
$$

Where $f_{\max }$ is frequency at maximum imaginary impedance.

Surface analysis of protective film

Mild steel specimen was immersed in the inhibitor system for a period of one day. After one day the specimen was taken out, dried and subjected to various surface analysis techniques.

- FTIR spectra were recorded in Perkin-Elmer make, model spectrum two.

- SEM images were recorded in Cartizers make model EVO-18.

- Vicker hardness was recorded in Shimadzu make model HMV-27.

- UV visible spectra were recorded in a Systronics double beam UV-VIS Spectrophotometer 2202

- Fluorescence spectra were recorded in a Shimadzu Spectro fluorophotometer.

Sea water

The composition of sea water used in this study is given in Table 1. Sea water was collected in Bay of Bengal, located at Kanampadi, East Coast Road, Chennai, India.

\begin{tabular}{|c|c|c|c|}
\hline Physical examination & Acceptable limit & $\begin{array}{c}\text { Permissible } \\
\text { limit }\end{array}$ & Sample value \\
\hline 1. Color & & & Colorless \& Clear \\
\hline 2. Odour & Unobjectionable & & Unobjectionable \\
\hline 3. Turbidity NT units & 1 & 5 & 0.2 \\
\hline 4. Total dissolved solids $\mathrm{mg} / 1$ & 500 & 2000 & 29400 \\
\hline 5. Electrical conductivity micro $\mathrm{mho} / \mathrm{cm}$ & & & 42000 \\
\hline Chemical examination & Acceptable limit & $\begin{array}{c}\text { Permissible } \\
\text { limit }\end{array}$ & Sample value \\
\hline 6. $\mathrm{pH}$ & $6.5-8.5$ & $6.5-8.5$ & 7.46 \\
\hline 7. $\mathrm{pH}$ Alkalinity as $\mathrm{CaCO}_{3}$ & & 0 & 0 \\
\hline 8. Total Alkalinity as $\mathrm{CaCO}_{3}$ & 200 & 600 & 140 \\
\hline 9. Total Hardness as $\mathrm{CaCO}_{3}$ & 200 & 600 & 4000 \\
\hline 10. Calcium as $\mathrm{Ca}$ & 75 & 200 & 1200 \\
\hline
\end{tabular}

Table 1. Composition of sea water. 


\begin{tabular}{lccc}
\hline \multicolumn{1}{c}{ Chemical examination } & Acceptable limit & $\begin{array}{c}\text { Permissible } \\
\text { limit }\end{array}$ & Sample value \\
\hline 11. Magnesium as $\mathrm{Mg}$ & 30 & 100 & 240 \\
12. Iron as $\mathrm{Fe}$ & 0.1 & 1 & 0 \\
13. Magnesium as $\mathrm{Mg}$ & 0.1 & 0.3 & $\mathrm{NT}$ \\
14. Free ammonia as $\mathrm{NH}_{3}$ & 0.5 & 0.5 & 0.48 \\
15. Nitrite as $\mathrm{NO}_{2}$ & 0.5 & 0.5 & 0.104 \\
16. Nitrate as $\mathrm{NO}_{3}$ & 45 & 45 & 25 \\
17. Chloride as $\mathrm{Cl}$ & 250 & 1000 & 15000 \\
18. Fluoride as $\mathrm{F}$ & 1 & 1.5 & 1.8 \\
19. Sulphate as $\mathrm{SO}_{4}$ & 200 & 400 & 1170 \\
20. Phosphate as $\mathrm{PO}_{4}$ & 0.5 & 0.5 & 1.47 \\
21. Tids Test $4{\mathrm{hrs} \mathrm{as} \mathrm{O}_{2}}$ & & $\mathrm{NT}$ \\
\hline
\end{tabular}

\section{Results and Discussion}

An aqueous extract of a plant material, namely, turmeric powder (Curcuma longa) has been prepared by boiling $10 \mathrm{~g}$ of shade dried turmeric powder, filtering the suspended impurities and making up to $100 \mathrm{ml}$ in a standard measuring flask. The extract was used to control the corrosion of mild steel in sea water. The findings will be useful in cooling water systems. These inhibitors may be added to cooling water carried by pipelines made of mild steel. The inhibition efficiency of the inhibitor system was evaluated by weight loss method. The mechanistic aspects were studied by polarization study and AC impedance spectra.

Analysis of results of weight loss method

Inhibition of corrosion of mild steel in sea water

The weight loss method has been used to evaluate the inhibition efficiency of turmeric extract in controlling corrosion of mild steel in sea water. The inhibition efficiencies (IE) of turmeric extract in controlling corrosion of mild steel are given in Table 2 . The corrosion rates are also given in the Table 2.

Table 2. Corrosion rates and inhibition efficiency (IE) of inhibitor system [turmeric extract (TE)] in controlling corrosion of mild steel in sea water.

\begin{tabular}{ccc}
\hline Volume of turmeric extract, $\mathbf{m l}$ & Corrosion rate, mdd & Inhibition efficiency, $\%$ \\
\hline 0 & 35.88 & - \\
2 & 16.15 & 55 \\
4 & 11.48 & 68 \\
\hline
\end{tabular}




\begin{tabular}{ccc}
\hline Volume of turmeric extract, $\mathbf{m l}$ & Corrosion rate, mdd & Inhibition efficiency, \% \\
\hline 6 & 8.61 & 76 \\
8 & 5.02 & 86 \\
10 & 0.72 & 98 \\
\hline
\end{tabular}

The surface coverage of plant extract in controlling corrosion of mild steel immersed in sea water are given in Table 3.

Table 3. Inhibition efficiency and surface coverage.

\begin{tabular}{ccc}
\hline Volume of turmeric extract, $\mathbf{m l}$ & IE, $\boldsymbol{\%}$ & Surface coverage, $\boldsymbol{\theta}=\mathbf{I E} / \mathbf{1 0 0}$ \\
\hline 2 & 55 & 0.55 \\
4 & 68 & 0.68 \\
6 & 76 & 0.76 \\
8 & 86 & 0.86 \\
10 & 98 & 0.98 \\
\hline
\end{tabular}

\section{Adsorption isotherm}

Inhibition of corrosion of metals and alloys are mainly due to adsorption of inhibitor molecules on the metal surface. In the case of natural product extracts, the active principles of the extracts get adsorbed on the metal surface.

Table 4. Parameters for the plot of Langmuir adsorption isotherm $C v s C / \theta$.

\begin{tabular}{ccc}
\hline $\boldsymbol{C}$ & $\boldsymbol{C} / \boldsymbol{\theta}$ \\
\hline 2 & 3.64 \\
4 & 5.88 \\
6 & 7.89 \\
8 & 9.30 \\
10 & 10.20 \\
\hline
\end{tabular}

The surface coverage $\theta$ of the inhibitor on the metal surface was calculated from the relation, $\theta=\mathrm{IE} \% / 100$

A plot of $C$ is $C / \theta$ was made. A straight line was obtained. The $R^{2}$ value was very high (0.972). All these observations indicate that adsorption of inhibitor molecules on the metal surface obey Langmuir adsorption isotherm. 


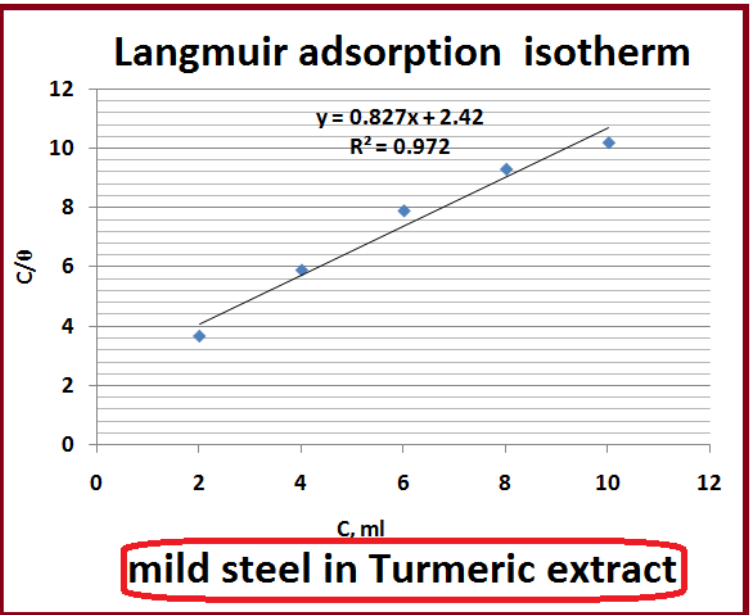

Figure 1. Adsorption isotherm on mild steel immersed in sea water in presence of inhibitor.

\section{Analysis of polarization curves}

Corrosion parameters derived from polarization study, namely corrosion potential $\left(E_{\text {corr }}\right)$, Tafel slope $\left(b_{\mathrm{c}}, b_{\mathrm{a}}\right)$, Linear polarization resistance $(L P R)$ values and corrosion current $\left(I_{\text {corr }}\right)$ values are given in Table 5. The polarization curves of mild steel (MS) immersed in sea water the absence and presence of inhibitor system are shown in Figure 2.

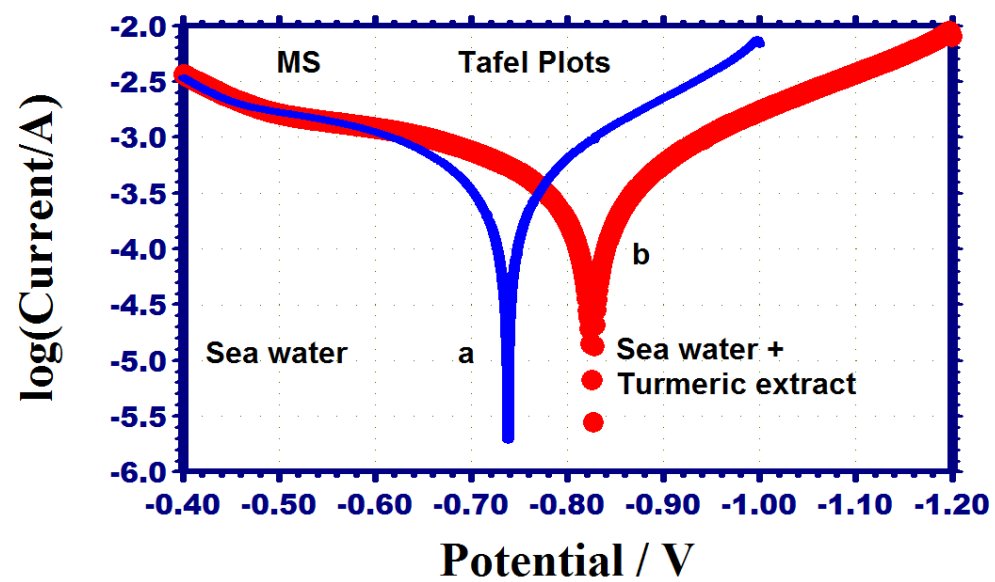

Figure 2. Polarization curves of mild steel immersed in various test solutions. (a) sea water (b) sea water+tumeric extract.

Table 5. Corrosion parameters of mild steel immersed in sea water in the absence and presence of an aqueous extract of turmeric powder obtained by polarization study.

\begin{tabular}{|c|c|c|c|c|c|}
\hline System & $E_{\text {corr, }}, \mathrm{V} / \mathrm{SCE}$ & $b_{c}$, V/decade & $b_{\mathrm{a}}, \mathrm{V} /$ decade & $\begin{array}{c}L P R, \\
\text { Ohm cm }\end{array}$ & $I_{\text {corr }}, \mathrm{A} / \mathrm{cm}^{2}$ \\
\hline Sea water & -0.738 & 5.763 & 4.479 & 106 & $4.006 \times 10^{-4}$ \\
\hline $\begin{array}{c}\text { Sea water+turmeric } \\
\text { extract }\end{array}$ & -0.827 & 5.632 & 4.354 & 141 & $3.08 \times 10^{-4}$ \\
\hline
\end{tabular}


It is observed from the Table 5 that when mild steel is immersed in sea water, the corrosion potential is $-0.738 \mathrm{~V} / \mathrm{SCE}$. The $L P R$ value is $106 \mathrm{Ohm} \mathrm{cm}{ }^{2}$. The corrosion current value is $4.006 \times 10^{-4} \mathrm{~A} / \mathrm{cm}^{2}$. It is inferred from the Table 5, that in presence of inhibitor, the corrosion potential is shifted from -0.738 to $-0.827 \mathrm{~V} / \mathrm{SCE}$. This is a cathodic shift. It suggests that the cathodic reaction is controlled predominantly. The LPR value increases from $106 \mathrm{Ohm} \mathrm{cm}^{2}$ to $141 \mathrm{Ohm} \mathrm{cm}$ (Figure 3). Correspondingly the corrosion current value decreases from $4.006 \times 10^{-4} \mathrm{~A} / \mathrm{cm}^{2}$ to $3.08 \times 10^{-4} \mathrm{~A} / \mathrm{cm}^{2}$. These observations confirm that a protective film is formed on the metal surface. This controls the corrosion of metal [16-20].

This is due to the fact in presence of inhibitor system, the active principles of the inhibitor system are adsorbed on the metal surface and a protective film is formed. This prevents the corrosion of metal and hence LPR value increases and corrosion current value decreases.

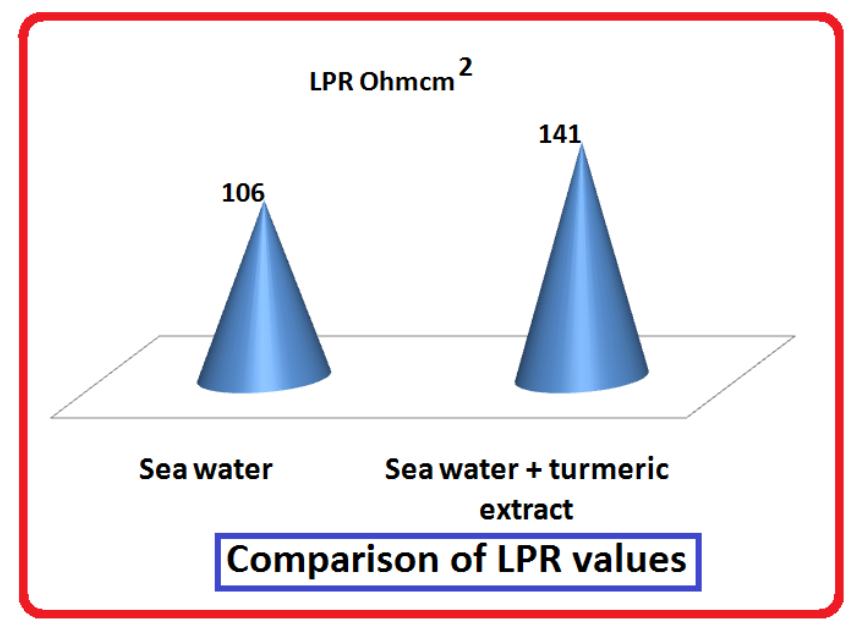

Figure 3. Comparison of LPR values.

Analysis of AC impedance spectra

The protective film formed on the metal surface is confirmed by AC impedance spectra. If a protective film is formed on the metal surface, the charge transfer resistance $\left(R_{\mathrm{t}}\right)$ value increases; double layer capacitance value $\left(C_{\mathrm{dl}}\right)$ decreases and the impedance [ $\left.\log (Z / \mathrm{ohm})\right]$ value increases [21-25].

The AC impedance spectra of mild steel immersed in sea water in the absence and presence of inhibitor (turmeric extract) are shown in Figure 4 (Nyquist plots), Figures 5 and 6 (Bode plots). The corrosion parameters, namely $R_{\mathrm{t}}, C_{\mathrm{dl}}$ and impedance values, are given in Table 6. 


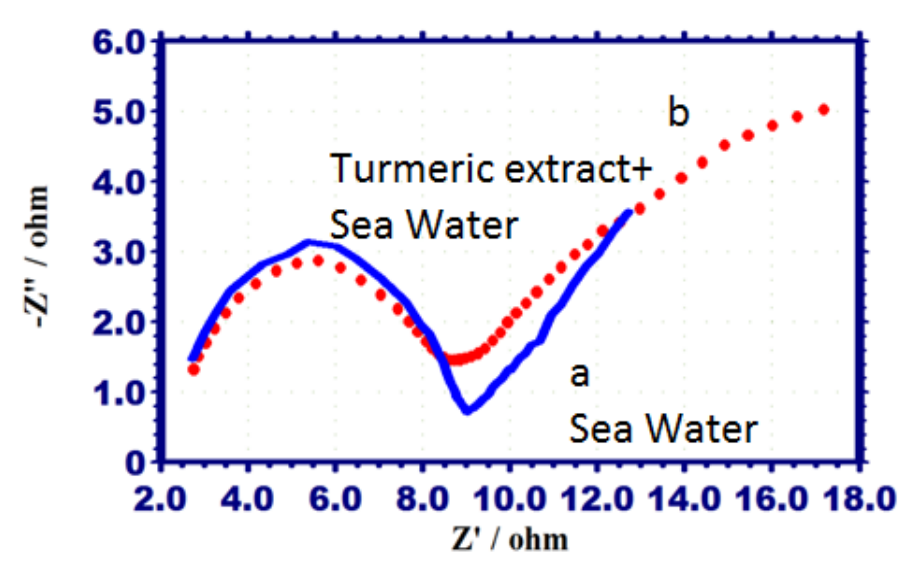

Figure 4. AC impedance spectra of mild steel immersed in various test solution (Nyquist Plot); (a) SW; (b) SW + turmeric extract.
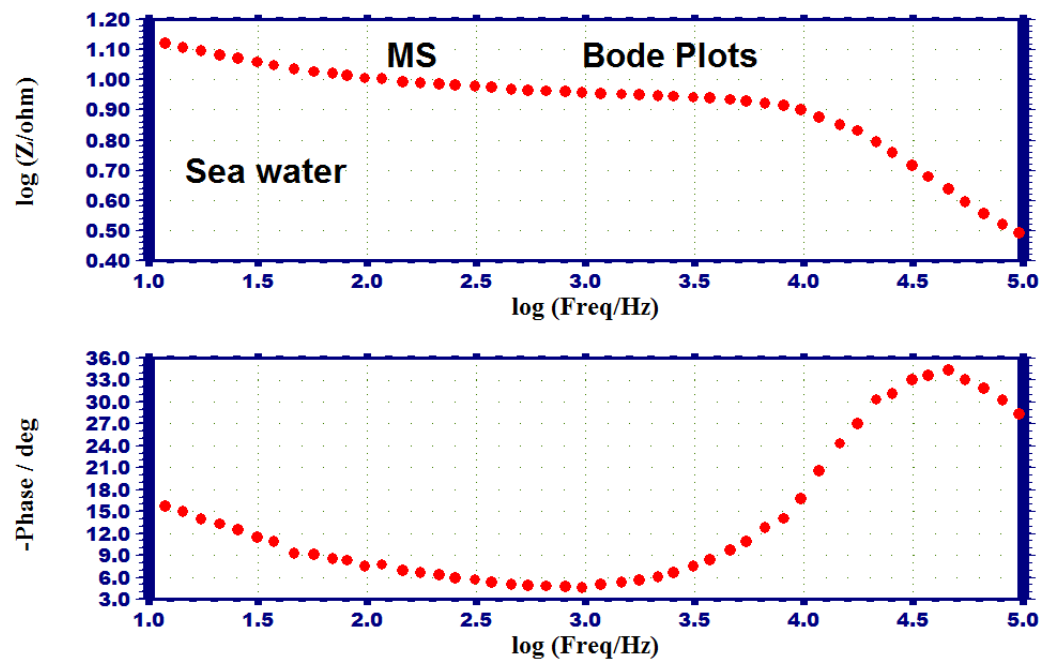

Figure 5. AC impedance spectra of mild steel immersed in SW (Bode plots).
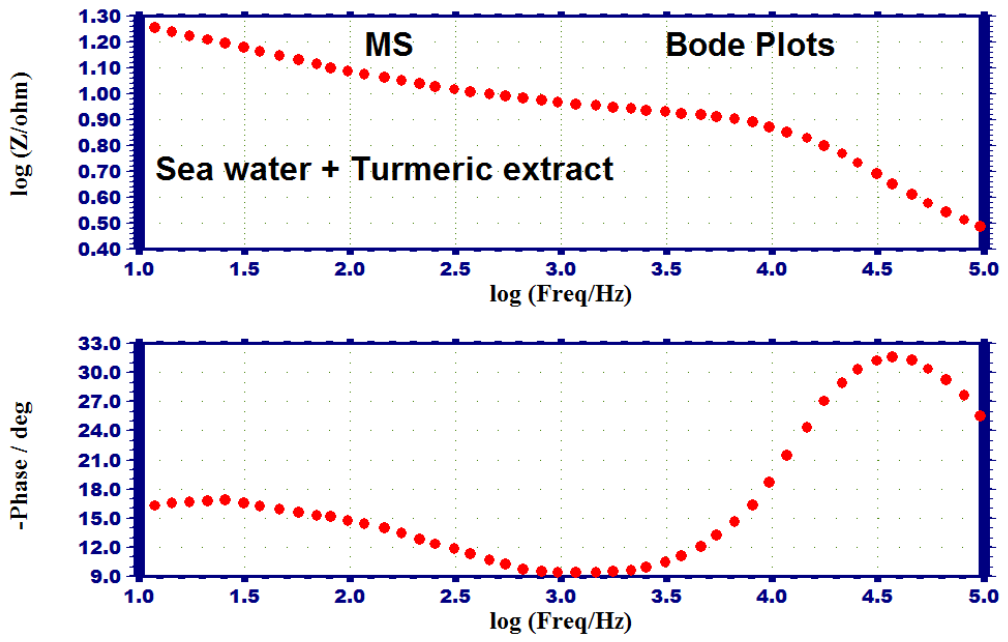

Figure 6. AC impedance spectra of mild steel immersed in SW+turmeric extract (Bode plots). 
Table 6. Corrosion parameters of mild steel (MS) immersed in simulated sea water (SW) in the absence and presence of an aqueous extract of a turmeric extract (Curcuma longa) obtained by AC impedance spectra.

\begin{tabular}{cccc}
\hline System & $\boldsymbol{R}_{\mathbf{t}}, \mathbf{O h m ~ \mathbf { ~ m } ^ { 2 }}$ & $\boldsymbol{C}_{\mathbf{d l}}, \mathbf{F} / \mathbf{c m}^{2}$ & $\begin{array}{c}\text { Impedance, } \\
\boldsymbol{l o g}(\mathbf{Z} / \mathbf{O h m})\end{array}$ \\
\hline SW & 10.10 & $5.05 \times 10^{-8}$ & 1.119 \\
$\mathrm{SW}+10 \mathrm{ml}$ of turmeric extract & 14.36 & $3.55 \times 10^{-8}$ & 1.250 \\
\hline
\end{tabular}

It is observed from the Table 6 that, when MS is immersed in SW, the $R_{\mathrm{t}}$ value is 10.10 Ohm cm $\mathrm{cm}^{2}$. The $C_{\mathrm{dl}}$ value is $5.05 \times 10^{-8} \mathrm{~F} / \mathrm{cm}^{2}$. The impedance value is 1.119 .

In the presence of the inhibitor, the $R_{\mathrm{t}}$ value increases from $10.10 \mathrm{Ohm} \mathrm{cm}^{2}$ to 14.36 Ohm cm $\mathrm{cm}^{2}$ (Figure 7 ). The $C_{\mathrm{dl}}$ value decreases from $5.05 \times 10^{-8} \mathrm{~F} / \mathrm{cm}^{2}$ to $3.55 \times 10^{-8}$ $\mathrm{F} / \mathrm{cm}^{2}$. The impedance value increases from 1.119 to 1.250 . This indicates that a protective film is formed on the metal surface. Hence the corrosion resistance increases in presence of turmeric extract.

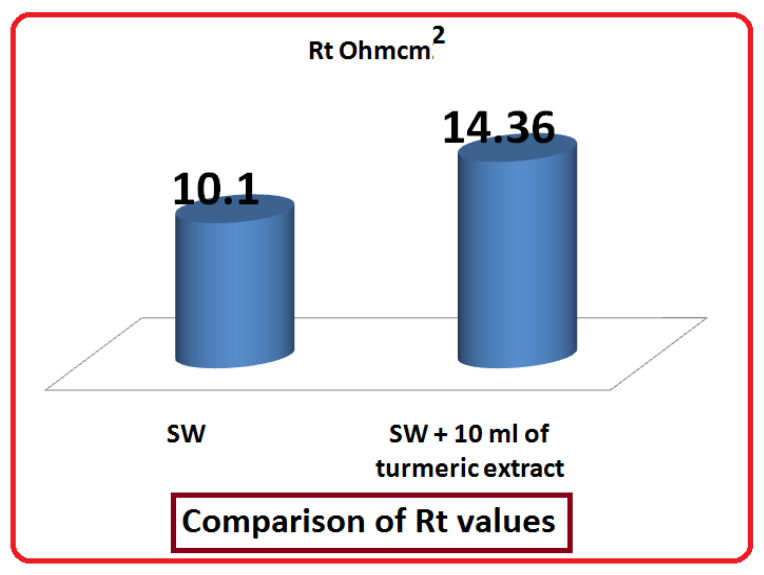

Figure 7. Comparison of $R_{\mathrm{t}}$ values.

Implication: Mild steel samples were immersed in sea water with turmeric extract (curcuma longa) to evaluate corrosion inhibition efficiency of the plant extract. The inhibition efficiency increases with the increase in concentration of plant extract. Inhibition efficiency up to $98 \%$ for mild steel was achieved. The results indicate that the corrosion rate decreases, as the concentration of plant extract increases and simultaneously it enhances the inhibition efficiency of the samples. This finding may find application in cooling water industry. To prevent corrosion of mild steel pipelines carrying sea water, the plant extract under investigation may be added, along with sea water.

Analysis of UV-visible absorption spectra

UV-visible absorption spectra have been used in corrosion inhibition study. UV-visible absorption spectrum of an aqueous extract of turmeric powder is shown in Figure 8. Peaks 
appear at $351.2 \mathrm{~nm}, 578 \mathrm{~nm}$ and $628.4 \mathrm{~nm}$. A few crystals of ferrous sulphate were added to the solution and shaken well. UV-visible absorption spectrum of this solution is shown Figure 9. Peaks appear at $347.6 \mathrm{~nm}$ and $578 \mathrm{~nm}$ and $624 \mathrm{~nm}$. Shifts in peak positions are observed. There is change in intensity of the peaks. This spectrum is due to the formation of a complex in solution between $\mathrm{Fe}^{2+}$ and active principle of turmeric extract (Curcumin).

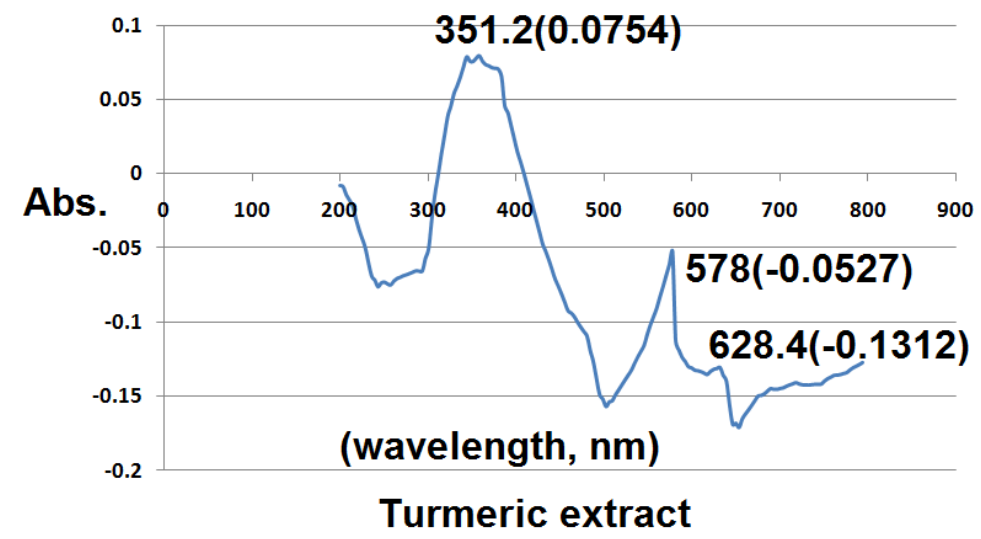

Figure 8. UV-visible absorption spectrum of turmeric extract.

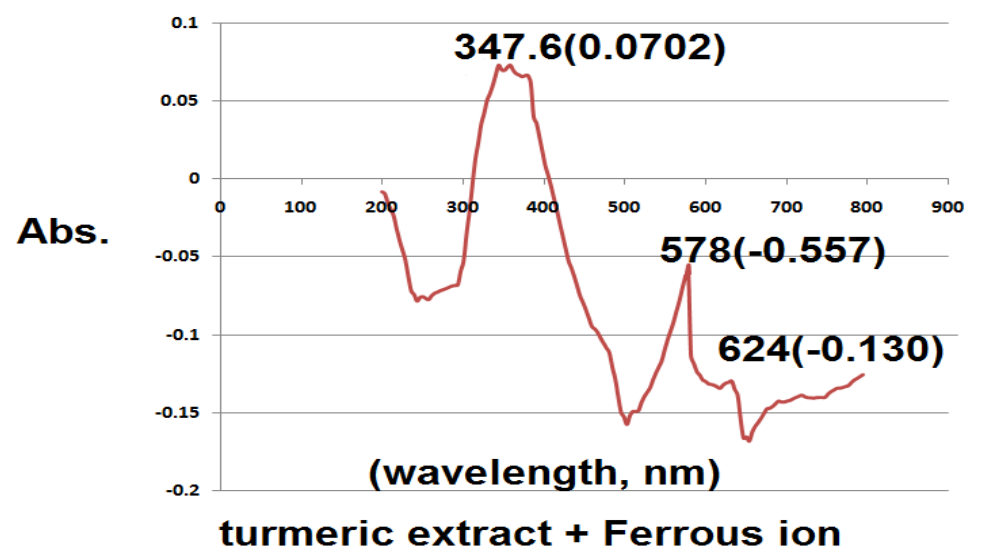

Figure 9. UV-visible absorption spectrum of turmeric extract $+\mathrm{Fe}^{2+}$ ion.

\section{Analysis of Fluorescence spectra}

The $\mathrm{Fe}^{2+}-$ Curcumin complex in solution was prepared by mixing ferrous sulphate crystals with an aqueous solution of turmeric extract. The fluorescence spectrum of this complex $\left(\lambda_{\text {ex }}=300 \mathrm{~nm}\right)$ is shown in Figure 10. A peak appears at $580 \mathrm{~nm}$.

The fluorescence spectrum of the protective film formed on metal surface after immersion in the solution containing $10 \mathrm{ml}$ of extract in sea water is shown in Figure 11. A peak appears at $579.5 \mathrm{~nm}$. This peak is very similar to the peak of $\mathrm{Fe}^{2+}-$ Curcumin complex. This confirms that the protective film consist of $\mathrm{Fe}^{2+}-$ Curcumin complex formed on the metal surface. It is observed that the intensity of the peak is low. This is due to the fact that 
in the solid state, there is restriction in the movement of electrons. Thus it is concluded the protection film consist of $\mathrm{Fe}^{2+}-$ Curcumin complex.

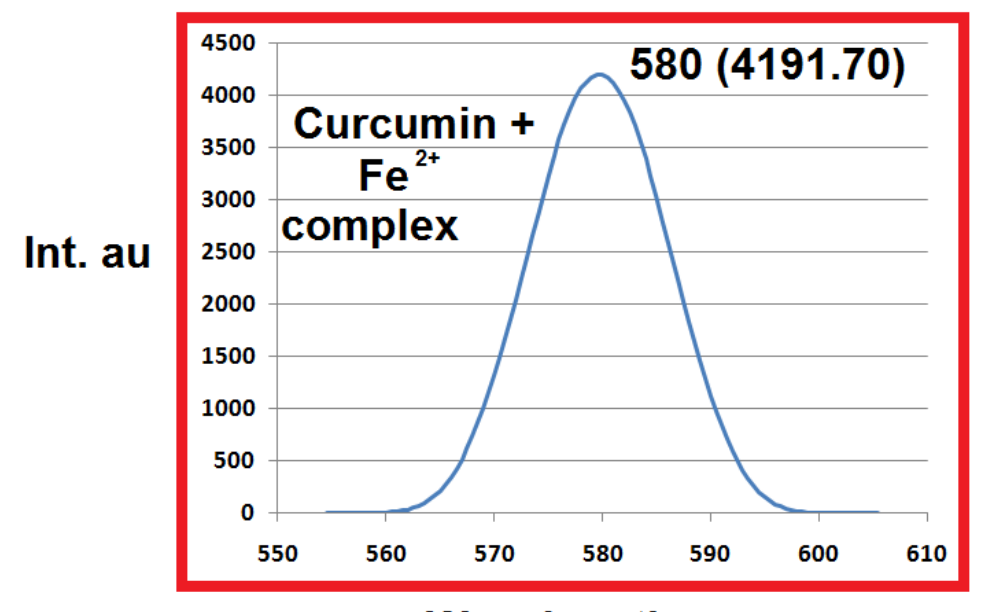

Wavelength, $\mathrm{nm}$

Figure 10. Fluorescence spectrum of turmeric extract $+\mathrm{Fe}^{2+}$.

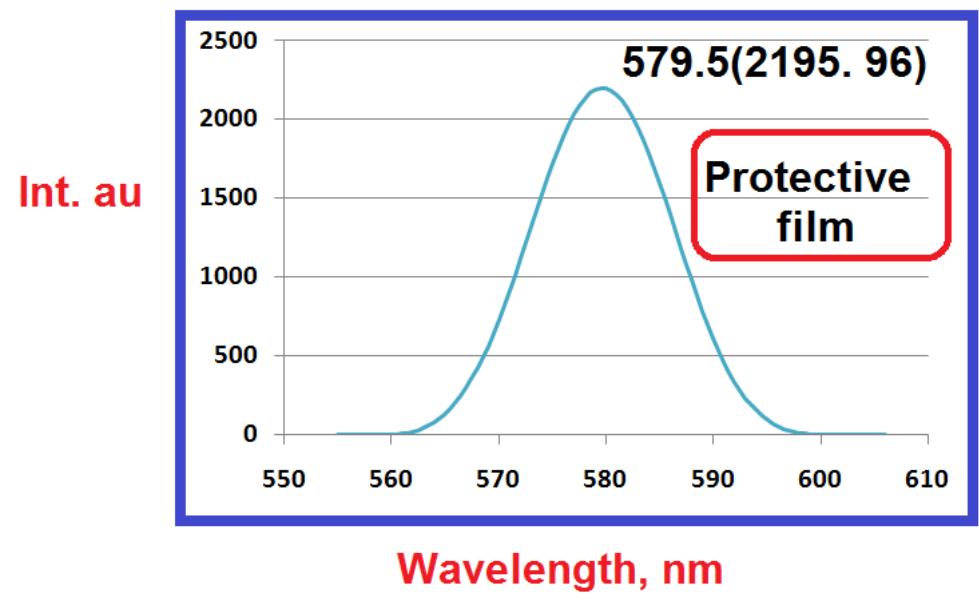

Figure 11. Fluorescence spectrum of protective film.

Analysis of SEM

A scanning electron microscope (SEM) is a type of electron microscope that produces images of a sample by scanning the surface with a focused beam of electrons. The electrons interact with atoms in the sample, producing various signals that contain information about the surface topography and composition of the sample. The electron beam is scanned in a raster scan pattern, and the position of the beam is combined with the intensity of the detected signal to produce an image. In the most common SEM mode, secondary electrons emitted by atoms excited by the electron beam are detected using a secondary electron detector (Everhart-Thornley detector). The number of secondary electrons that can be detected, and thus the signal intensity, depends, among other things, on specimen topography. SEM can achieve resolution better than 1 nanometer. 
SEM analysis has been widely used in corrosion inhibition study. SEM images are recorded for polished metal surface, metal surface immersed in corrosive medium and metal surface immersed in corrosive medium containing the inhibitor system. In the present study

SEM images were recorded for polished mild steel surface (system A), polished mild steel surface immersed in corrosive medium (SW) (system B) and polished mild steel surface immersed in corrosive medium (SW) containing the inhibitor system (system C). The images are shown in Figures 12-14.

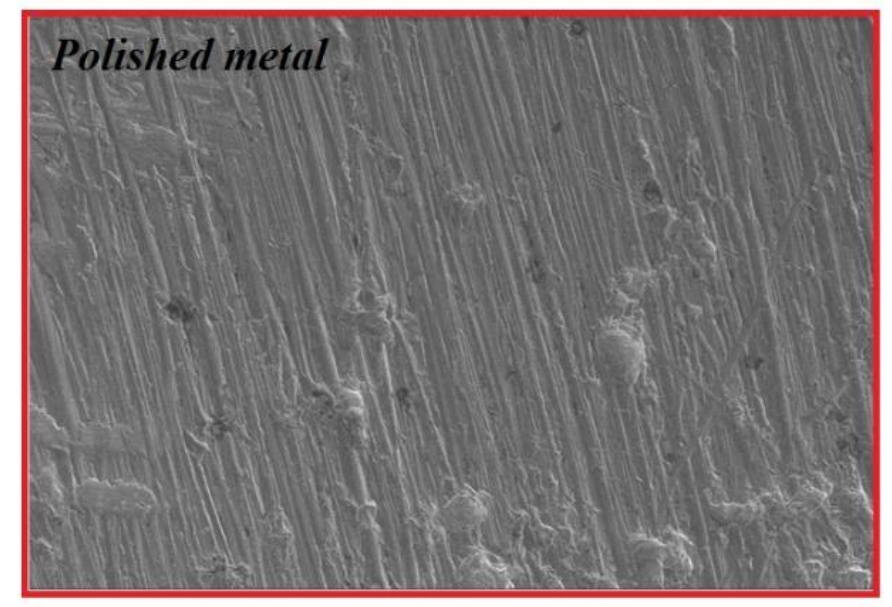

\section{Polished metal}

Figure 12. SEM image of polished metal.

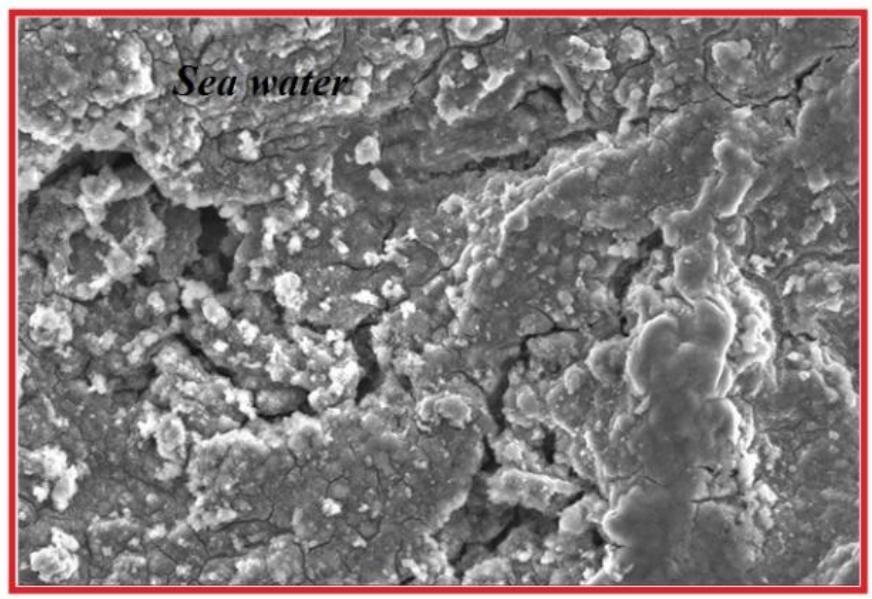

\section{Sea water}

Figure 13. SEM image of corroded metal (sea water). 


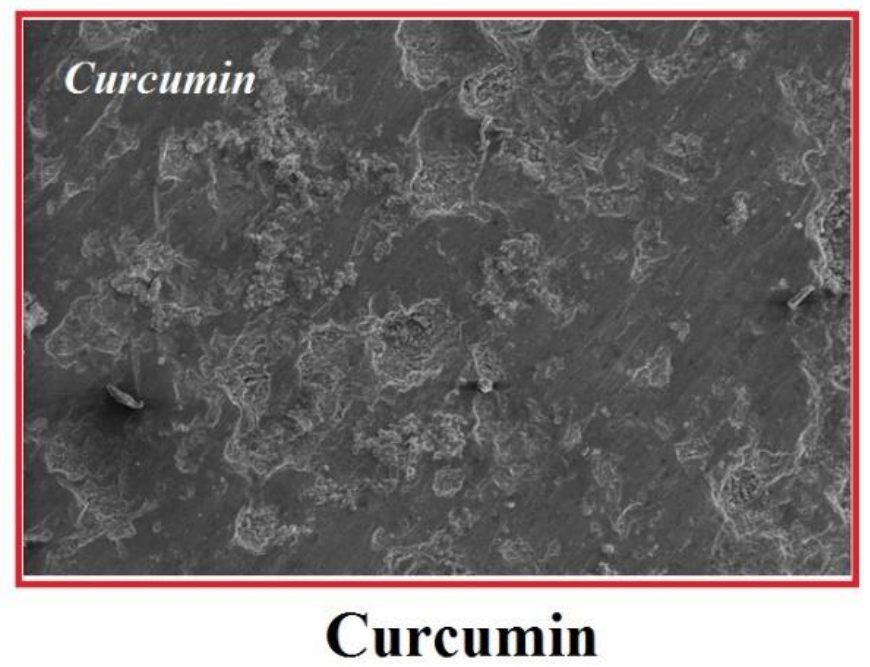

Figure 14. SEM image of protective film.

It is observed that for system A (polished mild steel surface) the surface is very smooth. For system B (polished mild steel surface immersed in corrosive medium [SW]) the surface is very rough. Pits are noticed due to corrosion. For system $\mathrm{C}$ (polished mild steel surface immersed in corrosive medium [SW] containing the inhibitor system), the surface is smooth, due to the formation of protective film. Thus the SEM is used in corrosion inhibition study.

\section{Analysis of Vicker hardness}

The Vickers test is often easier to use than other hardness tests since the required calculations are independent of the size of the indenter, and the indenter can be used for all materials irrespective of hardness. The basic principle, as with all common measures of hardness, is to observe a material's ability to resist plastic deformation from a standard source. The Vicker test can be used for all metals and has one of the widest scales among hardness tests. The unit of hardness given by the test is known as the Vickers Pyramid Number (HV) .

The hardness was measured for polished mild steel surface (system A), polished mild steel surface immersed in corrosive medium (sea water) (system B) and polished mild steel surface immersed in corrosive medium (sea water) containing the inhibitor system (system C). The values are given in Tables 7 and 8 . It is observed that for system A the hardness is high. For system B the hardness is low because the corroded surface contains iron oxide film which is porous and amorphous. The surface is very rough. Pits are noticed due to corrosion. For system $\mathrm{C}$ the surface is smooth, due to the formation of protective film. The hardness is in between that of system A and B. That is, lower than that of polished metal but higher than that of corroded surface. Thus the Vickers hardness is used in corrosion inhibition study.

Table 7. HV (average) for 25 gram load. 
Polished metal

Corroded metal sea water

Inhibited metal turmeric extract
106.5

99.5

112

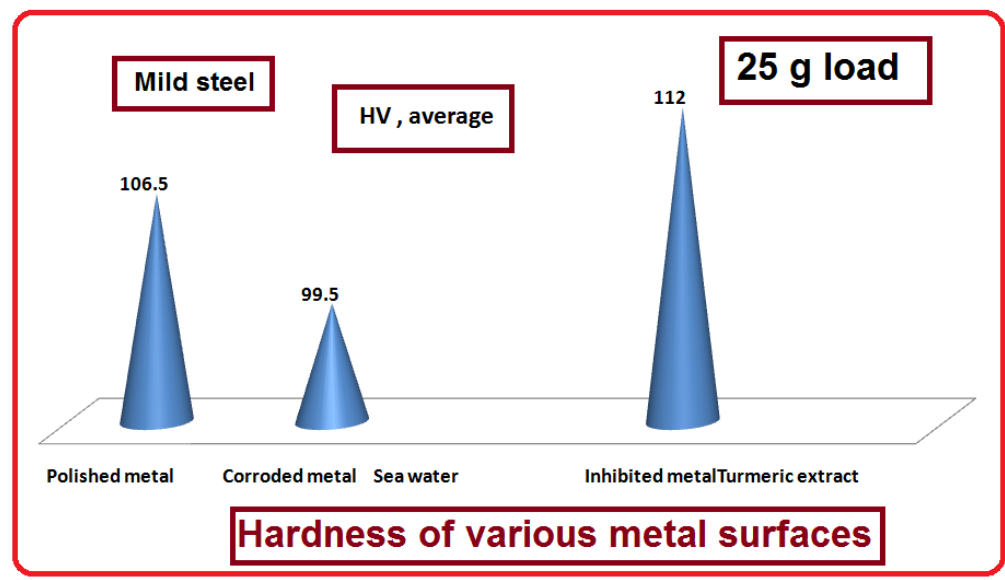

Figure 15. Hardness of various surfaces (25 g load).

Table 8. HV (average) for 50 gram load.

\begin{tabular}{cc}
\hline System & HV, average \\
\hline Polished metal & 161.5 \\
Corroded metal sea water & 157 \\
Inhibited metal turmeric extract & 222.5 \\
\hline
\end{tabular}

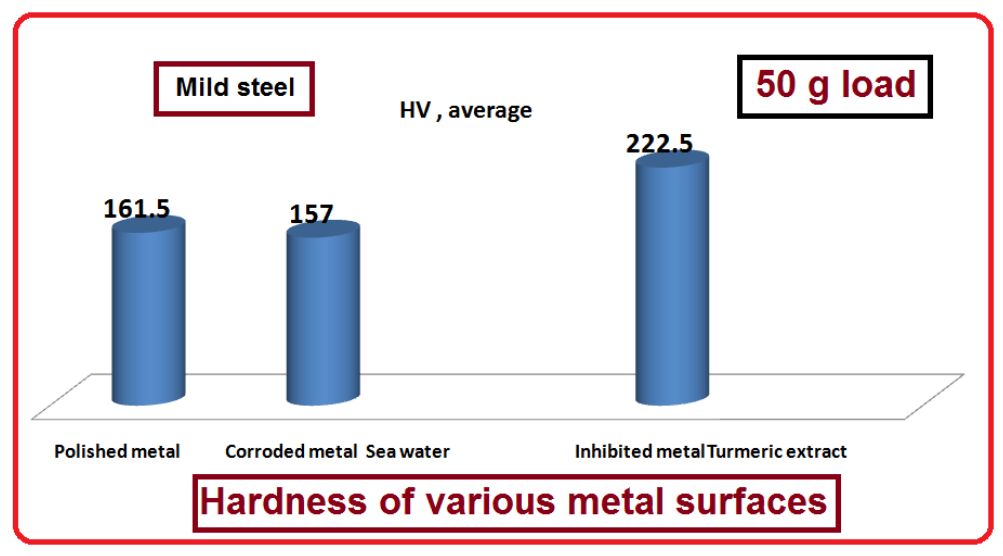

Figure 16. Hardness of various metal surfaces (50 g load).

\section{Analysis of FTIR spectra}

FTIR spectra have been used to confirm the formation of protective film on the metal surface, during corrosion inhibition process. In the present study, an aqueous extract of turmeric powder has been used as corrosion inhibitor. The main active principle of this extract is 
Curcumin (Figure 17). A few drops of the extract was placed on glass plate and dried. A solid mass was obtained. It was mixed with $\mathrm{KBr}$ and made in the pellet form and FTIR spectrum was recorded (Figure 18). The FTIR spectrum of the protective film formed on the metal surface after immersion for a period of one day, in the solution containing sea water and extract solution is shown in Figure 19.

It is observed from the Figures 17 and 18, that the stretching frequencies of various functional groups have shifted. The results are summarized in Table 9. The shifts in frequencies of various functional groups indicate that the inhibitor has coordinated with $\mathrm{Fe}^{2+}$ on the metal surface, through oxygen atoms of hydroxyl group, carbonyl group and alkyl aryl ether, and also through $\pi$-electrons of the alkene group and benzene ring. Thus the study leads to the conclusion that the protective film consists of iron curcumin complex formed metal surface.

Structure of curcumin

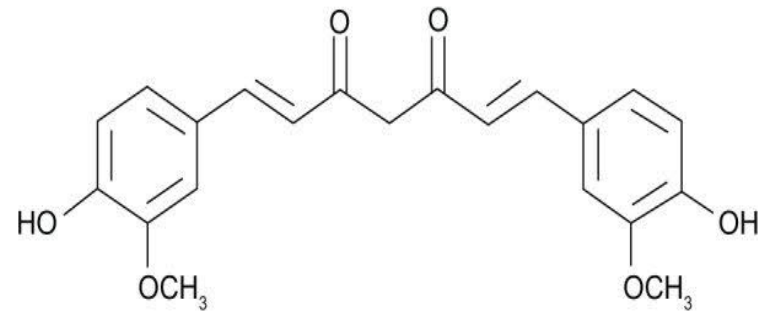

(1E,6E)-1,7-bis(4-hydroxy-3-methoxyphenyl)-1,6-heptadiene-3,5-dione

Figure 17. Structure of Curcumin.

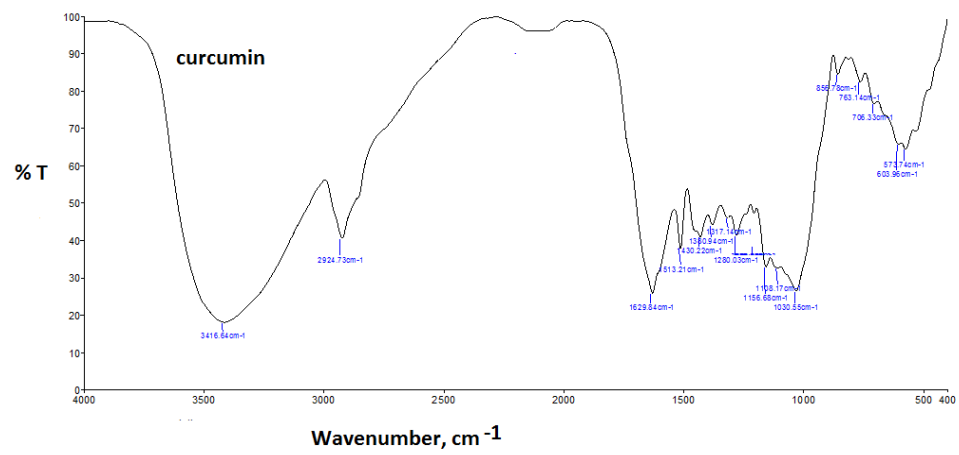

Figure 18. FTIR spectrum of Curcumin. 


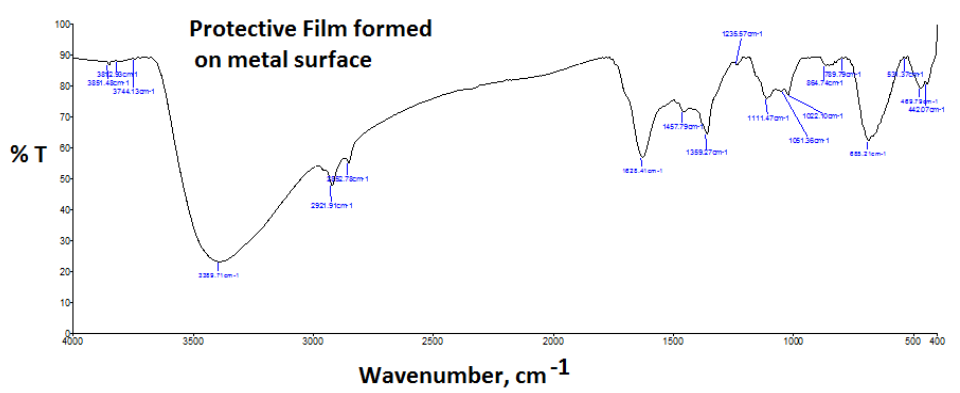

Figure 19. FTIR spectrum of protective film.

Table 9. Stretching frequencies of various functional groups.

\begin{tabular}{ccc}
\hline \multirow{2}{*}{ Various functional groups } & \multicolumn{2}{c}{ Stretching frequency, $\mathbf{c m}^{\mathbf{- 1}}$} \\
& $\begin{array}{c}\text { Active ingredient of inhibitor } \\
\text { (Curcumin) }\end{array}$ & $\begin{array}{c}\text { Protective film formed on } \\
\text { the MS surface }\end{array}$ \\
\hline OH & 3417 & 3390 \\
C=O & 1629 & 1628 \\
C=C (alkene) & 1513 & 1520 \\
C=C (aromatic ring) & 1430 & 1458 \\
C-O-C & 1157 & 1111 \\
\hline
\end{tabular}

\section{Conclusions}

In the present study an aqueous extract of turmeric powder has been used as corrosion inhibitor, to control corrosion of mild steel in sea water. Methods such as weight loss method, polarization study and AC impedance spectra have been used. The protective film has been analyzed by UV-visible spectra, Fluorescence spectra and FTIR spectra. The surface morphology has been analyzed by SEM. The Hardness of a metal before and after immersion have been determined. This study leads to the following conclusion:

- Weight loss study reveals that the maximum corrosion inhibition efficiency of $98 \%$ is offered by $10 \mathrm{ml}$ of turmeric extract.

- The adsorption study reveals that the active principles (Curcumin) are adsorbed on metal surface by Langmuir absorption isotherm.

- Polarization study reveals that the inhibitor function as cathodic inhibitor, because the corrosion potential is shifted to more negative side.

- AC impedance spectra confirm the formation of a protective film on the metal surface.

- Fluorescence spectra confirm that the protective film consists of $\mathrm{Fe}^{2+}-$ Curcumin complex formed on the anodic sites of the metal surface.

- This is confirmed by FTIR spectra. 
- Vickers hardness (HV) study reveals that in presence of inhibitors, the hardness of the metal increases. In the absence of inhibitors (corrosive medium-sea water), the hardness of the metal decreases.

- These findings may be used in cooling water systems where sea water can be used as coolant.

\section{Scope for further study}

In the present study an aqueous extract of turmeric powder has been used as corrosion inhibitor, to control corrosion of mild steel in sea water. Methods such as weight loss method, polarization study and AC impedance spectra have been used. The protective film has been analyzed by UV-visible spectra, Fluorescence spectra and FTIR spectra. The surface morphology has been analyzed by SEM. The Hardness of a metal before and after immersion have been determined. The study can be extended further:

- Other metals such as copper and other alloys such as SS316 L can be used.

- Instead of sea water, ground water and well water can be used.

- AFM study can be used.

- Contact angle measurement can be carried out.

\section{References}

1. https://www.finishing.com/library/pennisi/corrosion.html

2. S. Jyothi, Y.V.S. Rao and P.S.S. Ratnakumar, Rasayan J. Chem., 2019, 12, no. 2, 537544. doi: $10.31788 /$ RJC.2019.1225054

3. S. Rajendran, R. Srinivasan, R. Dorothy, T. Umasankareswari and A.A. Hashem, Int. J. Corros. Scale Inhib., 2019, 8, no. 3, 473-479. doi: 10.17675/2305-6894-2019-8-3-12

4. O. Olawale, B.T. Ogunsemi, O.O. Agboola, M.B. Ake and G.O. Jawando, Int. J. Mech. Eng. Technol., 2018, 9, 282-287.

5. R.F.B. Cordeiro, A.J.S. Belati, D. Perrone and E. D'Elia, Int. J. Electrochem. Sci., 2018, 13, 12188-12207. doi: $10.20964 / 2018.12 .29$

6. S.A. Umoren, M.M. Solomon, I.B. Obot and R.K. Suleiman, J. Adhes. Sci. Technol., 2018, 32, 1934-1951. doi: $10.1080 / 01694243.2018 .1455797$

7. F. El-Taib Heakal, M.A. Deyab, M.M. Osman and A.E. Elkholy, Desalination, 2018, 425, 111-122. doi: 10.1016/j.desal.2017.10.019

8. R.S. Trindade, M.R. Dos Santos, R.F.B. Cordeiro and E. D'Elia, Green Chem. Lett. Rev., 2017, 10, 444-454. doi: 10.1080/17518253.2017.1398354

9. P. Parthipan, J. Narenkumar, P. Elumalai, A. Agrawal, A. Rajasekar, J. Mol. Liq., 2017, 240, 121-127. doi: 10.1016/j.molliq.2017.05.059

10. A. Salhi, A. Bouyanzer, I. El Mounsi, B. Hammouti and J. Costa, Der Pharm. Lett., 2016, 8, 79-89.

11. M.A. Khaldi, Asian J. Chem., 2016, 28, 2532-2538. doi: 10.14233/ajchem.2016.20090 
12. S. Rajendran and G. Singh, Titanic corrosion, Jenny Stanford Pte. Ltd., Singapore, 2020, 169.

13. S. Akbarzadeh, M. Ramezanzadeh, B. Ramezanzadeh and G. Bahlakeh, J. Hazard. Mater., 2020, 390, 122147. doi: 10.1016/j.jhazmat.2020.122147

14. I.B. Onyeachu, M.M. Solomon, S.A. Umoren, I.B. Obot and A.A. Sorour, Desalination, 2020, 479, 114283. doi: 10.1016/j.desal.2019.114283

15. E. Ituen, E. Ekemini, L. Yuanhua, R. Li, A. Singh, Int. Biodeter. Biodegr., 2020, 149, 104935. doi: $10.1016 /$ j.ibiod.2020.104935

16. R. Nagalakshmi, L. Nagarajan, R.J. Rathish, S.S. Prabha, N. Vijaya, J. Jeyasundari and S. Rajendran, Int. J. Nano. Corr. Sci. Engg., 2014, 1, 39.

17. J.A. Thangakani, S. Rajendran, J. Sathiabama, R.M. Joany, R.J. Rathis and S.S. Prabha, Int. J. Nano. Corr. Sci. Engg., 2014, 1, 50.

18. A. Nithya, P. Shanthy, N. Vijaya, R.J. Rathish, S.S. Prabha, R.M. Joany and S. Rajendran, Int. J. Nano Corr. Sci. Engg., 2015, $2,1$.

19. A.C.C. Mary, S. Rajendran, H. Al-Hashem, R.J. Rathish, T. Umasankareswari and J. Jeyasundari, Int. J. Nano Corr. Sci. Engg., 2015, 1, 42.

20. A. Anandan, S. Rajendran, J. Sathiyabama and D. Sathiyaraj, Int. J. Corros. Scale Inhib., 2017, 6, no. 2, 132-141. doi: 10.17675/2305-6894-2017-6-2-3

21. C.O. Akalezi, C.E. Ogukwe, E.A. Ejele and E.E. Oguzie, Int. J. Corros. Scale Inhib., 2016, 5, no. 2, 132-146. doi: 10.17675/2305-6894-2016-5-2-3

22. T.A. Onat, D. Yiğit, H. Nazır, M. Güllü and G. Dönmez, Int. J. Corros. Scale Inhib., 2016, 5, no. 3, 273-281. doi: 10.17675/2305-6894-2016-5-3-7

23. A.S. Fouda, M.A. El-Morsy, A.A. El-Barbary and L.E. Lamloum, Int. J. Corros. Scale Inhib., 2016, 5, no. 2, 112-131. doi: 10.17675/2305-6894-2016-5-2-2

24. V.I. Vigdorovich, L.E. Tsygankova, E.D. Tanygina, A.Yu. Tanygin and N.V. Shel, Int. J. Corros. Scale Inhib., 2016, 5, no. 1, 59-65. doi: 10.17675/2305-6894-2016-5-1-5

25. P.N. Devi, J. Sathiyabama and S. Rajendran, Int. J. Corros. Scale Inhib., 2017, 6, no. 1, 18-31. doi: $\underline{10.17675 / 2305-6894-2017-6-1-2}$ 